\title{
Flexibility of the chest-lumbar region in athletic athletes
}

Keywords: flexibility of chest-lumbar region, masters athletes, Tokyo 2020 games, Usain St. Leo Bolt, flat grounding, two axes running

\section{Introduction}

Tokyo 2020 Olympic and Paralympic games (Tokyo 2020 Games) will be held in a year, which attract people from all over the world., ${ }^{1,2}$ Sports can empower the body and mind of everyone, including not only Olympians/Paralympians, but also top players, sports enthusiasts, Masters athletic athletes and people with health problems.

The authors have continued various activities in the Japan Masters Athletics (JMA) and in the medical practice and care. In other words, there were lots of opportunities for sports lectures, workshops, medical treatment and rehabilitation. ${ }^{3}$ Among them, we have trained some athletes for Tokyo Paralympics games. As a whole, we have broaden the adequate running tips and practice for wider range of the subjects. Its characteristic points include less tension, less injury, effective and faster method. Furthermore, we have been actually Masters athletes for long years. Currently, the author Bando has Tokushima prefecture record of $100 \mathrm{~m}$ sprint, and the first author Murakami has just established the Kagawa Masters records at $100 \mathrm{~m}$ and $200 \mathrm{~m}$.

Regarding top athletes in Japan, well-known sprinters include Sani Brown, Cambridge, Kiryu, Yamagata, Koike and others. They are all professionals for pursuit of the victory with occasional injuries. On the other hand, ordinary people aim for effective and safer running methods. In such cases, the clinical important points are not to increase muscle power, but to maintain relax, stretching and flexibility. ${ }^{4}$ This training goal was recognized and emphasized by the recent sprint by Koike with 9.98 seconds for $100 \mathrm{~m}$, where he always continues training method with slow and relaxed jogging.

There has been a common problem in sprint race from our advising and practice experiences. It is that the body trunk becomes stiff with excess tension. ${ }^{5}$ This phenomena may be derived from our mind and body without relaxation. If this happens, one cannot move trunk and legs smoothly. ${ }^{6}$ In this case, the power originates from the trunk, and smooth coordination of the chest, waist, pelvis and lower extremity is essential.

Authors have continued proposing the recommended method to run faster with more relaxed and less injured from short distances to long distances. The outlines of them are in the following:

i. Flat grounding: touch the ground on the entire foot sole and do not kick the ground by the toe of the foot, ${ }^{7}$

ii. Forward leaning: keep the body forward leaning straight from head to foot, and then it can be converted to forward power by utilizing the center of gravity of the body, ${ }^{8}$

iii. Two axes running: The locus of the sole is not found in one axis but two axes, and the center of gravity during the running period could be swing to the left and right.

As 1) an athlete make the toe weaken the tension, then 2) he can
Volume 4 Issue 5 - 2019

\author{
Mitsuru Murakami,' Hiroshi Bando, ${ }^{2,3}$ Akito \\ Moriyasu ${ }^{4,5}$ \\ Japan Masters Athletics, Kagawa division, vice-president, Japan \\ ${ }^{2}$ Medical Research, Tokushima University, Japan \\ 3 Japan Masters Athletics, Tokushima division, Japan \\ ${ }^{4}$ Fellow of Spine Dynamic Therapy Association (SDTA), Japan \\ ${ }^{5}$ Fellow of The Japan Athletes Rehabilitation Trainers Association \\ (JARTA), Japan
}

Correspondence: Hiroshi Bando, Medical Research,Tokushima University, Nakashowa I-6I, Tokushima 770-0943, Japan, Tel: +81-90-3 187-2485, Email pianomed@bronze.ocn.ne.jp

Received: July 26, 2019 | Published: September 10, 2019

lean the body forward deeply. By 2) deep forward leaning and 3) fluctuation of center of gravity in left and right, the power of forward direction would become stronger. ${ }^{9}$ In addition to these $1,2,3$ ), we introduce 4) the importance of practical flexibility of chest-lumbar region in this article.

As mentioned above, the recommended way of running would be flat grounding. The mechanisms include i) foot landing on the ground, ii) bending knees slightly immediately, iii) center of the gravity of the body can be dropped forward direction. ${ }^{10}$ This process can take most advantages of the extensional reflexes of hamstrings with knee flexion. Flat landing can obtain large rebound power from the land. ${ }^{11}$

The important law of the stretch-shortening cycle (SSC) is involved in this phenomenon. ${ }^{12}$ By SCC training with drop jumps, the triceps surae muscle-tendon unit (MTU) revealed the increased energy absorption and increased energy release during the concentric phase. ${ }^{13}$ Furthermore, actual SSC function is influenced by the timing / adjustment of motor responses and the anticipation for the performance. ${ }^{14}$

There are some famous athletic athletes who can run as almost above-mentioned way. One of them would be Usain St. Leo Bolt (1986-). He could historically set a number of records until 2002-2017 and was called as "The greatest sprinter of all time". The side view of his run is shown in Figure 1. The characteristic points are as follows: 1) when landing, the heel is slightly floating, but it is the method of flat grounding without force on the toe, 2) forward leaning, 3) two axes running with fluctuation of the center of weight. Moreover, it shows 4) flexibility from the chest to the lower back. ${ }^{15}$ The flexing action enhances forward power.

As a reference to the running method of Bolt, we have given advises to students and masters athletes for the flexibility of the chest and lumbar region (Figure 2). Due to this training, the author is convinced that advanced flexibility could bring a new record of the Masters Championship game. 

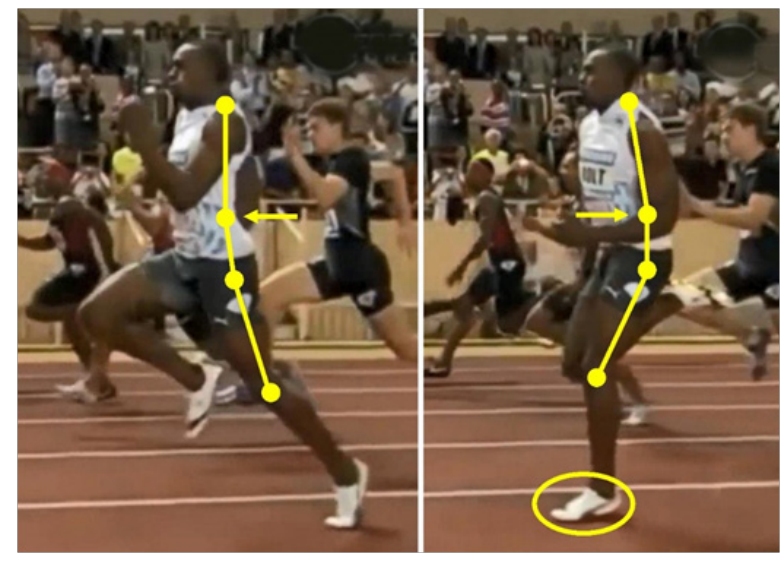

Figure I Side view of the sprint of $100 \mathrm{~m}$ by Usain St. Leo Bolt.
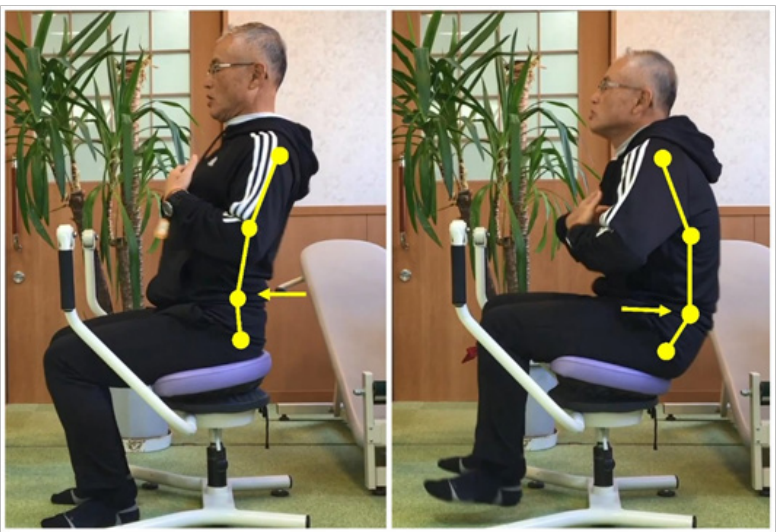

Figure 2 Side view of the practice for the flexibility of chest-lumbar region by Murakami.

There appear to be four necessary factors to this movement. They are 1) there is an overall flexibility of the neck, chest, lumbar and pelvic lines, ${ }^{10} 2$ ) this range has a somewhat wide range of motion, 3) this movement is smooth and interlocking ${ }^{16}$ and 4 ) there is an increased agility of the movement in rather wider flexible region. ${ }^{17}$ When these 4 factors can work together, an athlete can run fast smoothly without injuries.

It should be noted that for these movements, similar activities can be found in other fields. One is dance, and it is easy to understand when looking at the performance of South American Reggae. ${ }^{18}$ The neck, chest, lumbar and pelvic lines move back and forth accompanied by the beat rhythm. Simultaneously, the lower jaw also moves somewhat back and forth. The second is the movement when the animal pigeon walks forward. It is characterized by the head-bobbing which moves head and neck frequently back and forth. ${ }^{19}$ Just after the head and neck move forward with the center of the gravity together, the pigeon can move one foot forward at a time. All these movements are judged to be related to flexibility, interlocking, and agility.

In summary, we outlined the significance of the flexibility of chestlumbar region. The related training would affect various movements with probable beneficial effects. We hope that this article will be useful in several opportunities of sports and rehabilitation, and expect various development of future research.

\section{Funding}

None

\section{Acknowledgements}

None.

\section{Conflicts of interest}

The author declares no conflict of interest.

\section{References}

1. Bando H, Murakami M. Previous wisdom becomes reference for body movements leading to the olympics. J Nov Physiother. 2019;9:e154.

2. https://tokyo2020.org/en/

3. Murakami M, Bando H. Crucial point of how to run in the seminar and workshop in 2017 -tips for natural way of running without injury. Investigation of masters' athletes. Annual report of Japan Masters ' Athletics Association. 2018;36:21-22.

4. Zhao Y. Analysis on special training methods of track and field sprint. Adv Computer Sci Res. 2017;59:426-430.

5. Bando H, Murakami M. The important points in plantar region for relaxed standing and running. Res Rev Orhop. 2018;2(2):7-9.

6. Moriyasu A, Murakami M, Bando H. Some tips for the phenomenon of the yips in the sports. Res J Sport Health Psychol. 2019;1(1):101.

7. Hayant S, Prashant U. Effect of flat foot on the running ability of an athlete. Ind J Orthpaedic Surg. 2016;2(1):119-123.

8. Murakami M, Bando H. Same directionality of foot straight line and forward movement. ARC Journal of Research in Sports Medicine. 2019;4(1):14-16.

9. Bando H, Murakami M. The important points in plantar region for relaxed standing and running. Res Rev Orhop. 2018; 2(2):7-9.

10. Reenalda J, Maartens E, Buurke JH, et al. Kinematics and shock attenuation during a prolonged run on the athletic track as measured with inertial magnetic measurement units. Gait and amp; Posture. 2019;155160 .

11. Sandler M, Lee J. Barefoot running: how to run light and free by getting in touch with the earth. Crown/Archetype. 2011.

12. Verbickas V, Baranauskiene N, Eimantas N, et al. Effects of spring cycling and stretch-shortening cycle exercises on the neuromuscular, immune and stress indicators in young men. J Physiol Pharmaco. 2017;68(1):125-132.

13. Kümmel J, Cronin NJ, Kramer A, et al. Conditioning hops increase triceps surae muscle force and Achilles tendon strain energy in the stretch-shortening cycle. Scandinavian Journal of Medicine \& Science in Sports. 2018;28(1):126-137.

14. Helm M, Ritzmann R, Gollhofer A, et al. Anticipation modulates neuromechanics of drop jumps in known or unknown ground stiffness. Plos one. 2019;14(1):e0211276.

15. Moriyasu A, Bando H, Akayama R, et al. Thorax flexibility can be increased by standing pole exercise. Int J Phys Med Rehabil. 2017;6:444.

16. Bando H, Murakami M. Arches and points in the foot of running athletes. J Nov Physiother. 2019;9:405.

17. ATEŞ B. Age-related effects of speed and power on agility performance of young soccer players. Journal of Education and Learning. 2018;7(6):93-99.

18. Ayodele RB, Akinbiolai OO. Dance, physical fitness and nation building: what relationship?. Eur J Phys Educ Sport Sci. 2018; 4(10):147-158.

19. https://ssrn.com/abstract $=3397596$ 